Check for updates

Cite this: RSC Adv., 2018, 8, 1148

Received 13th November 2017 Accepted 21st December 2017

DOI: $10.1039 / c 7 r a 12387 f$

rsc.li/rsc-advances

\section{Influence of red palm oil on the physicochemical and sensory qualities of flavouring oil gravy for instant noodles}

\begin{abstract}
Xiaojing $\mathrm{Wu}^{a}$ Shimin $\mathrm{Wu},{ }^{\mathrm{D}}{ }^{* a b} \mathrm{Min} \mathrm{Ji}^{\mathrm{c}}$ and Jun Hao Yoong ${ }^{\mathrm{c}}$
The nutrition and flavour of instant noodles is largely attributed to added flavouring oil gravy. Herein, we evaluated the influence of red palm oil (RPO) on the physicochemical properties and sensory qualities by comparing palm oils and commercial oils and fats. The induction time for RPO (10.20 h) was higher than that for $5^{\circ}(7.20 \mathrm{~h})$ and $8^{\circ}(8.40 \mathrm{~h})$ palm oils. The RPO carotenoid, $\beta$-carotene and vitamin $\mathrm{E}$ content was $563.50,520.00$, and $364.00 \mathrm{mg} \mathrm{kg}^{-1}$, respectively. The carotenoid content of red sauce with RPO (RPR) and spicy sauce with RPO (SPR) gravies was 450.00 and $451.20 \mathrm{mg} \mathrm{kg}^{-1}$, respectively, far higher than those without RPO. The induction times of RPR and SPR were highest (16.65 h and $15.48 \mathrm{~h}$ ). The

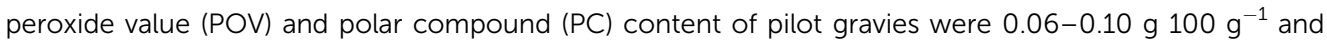
$11.00-15.00 \%$, respectively. Principal component analysis of electronic tongue results revealed that gravies containing RPO displayed higher repeatability, demonstrating the reliability of the method for detecting RPO.
\end{abstract}

\section{Introduction}

Instant noodles are an internationally important food eaten widely in East and Southeast Asian countries, and more than 80 other countries around the world. ${ }^{1}$ Their popularity is increasing due to the desirable flavour, affordable price, and rapid preparation time, which suits the modern, hectic lifestyle. However, over-consumption of instant noodles has been linked to health risks. ${ }^{2}$ To meet the health demands of consumers, the instant noodle industry is moving towards developing new ingredients and higher-quality products. Between 2013 and 2017, the volume of sales of high-quality instant noodles increased sharply, especially in East Asia.

High-quality instant noodles should be appealing to the senses and of high nutritional value, and the key to achieving this is the identification of suitable seasoning ingredients for packing together with the noodle block. In China, instant noodles are sold in various grades, shapes, and packages such as plastic bags, cups, and bowls. The noodle block is usually accompanied by three sachets containing dry seasoning powder, flavouring oil gravy, and dried vegetables or meats. The acceptability, flavour, and price of such products are becoming

${ }^{a}$ Department of Food Science and Technology, School of Agriculture and Biology, Shanghai Jiao Tong University, Dongchuan Road 800, Shanghai 200240, China. E-mail: wushimin@sjtu.edu.cn; Fax: +8621 34205717; Tel: +86 2134205717

${ }^{b}$ Key Laboratory of Urban Agriculture (South), Ministry of Agriculture, Dongchuan Road 800, Shanghai 200240, China

'Palm Oil Research and Technical Service Institute of MPOB, Shanghai 201108, China more closely linked to the nutritional quality and sensory properties of the enclosed flavouring oil gravy.

Flavouring oil gravy accounts for $10-20 \%$ of the total weight of the instant noodle product, and quality control personnel working in the instant noodle industry frequently receive complaints about the nutritional and sensory qualities of flavouring oil gravy. This is because it contributes significantly to the energy value, aroma, taste, and colour of the soup. Compared with the other components in the pack, the manufacture and formula of the flavouring oil gravy are more technologically demanding and complicated. Flavouring oil gravy is generally made of minced meat fried with oil, shallot, onion, garlic, and other spicy condiments. Normally, the oil accounts for $\sim 50 \%$ of the weight of the flavouring oil gravy. Vegetarians and some ethnic consumers require flavouring oil gravy to contain no animal fat additives, and most consumers prefer healthier components that are attractive in colour, pleasant in flavour, and without any rancid aroma. Thus, as one of the main components, the oil is a key ingredient contributing to the overall quality of the flavouring oil gravy.

Soybean oil is used widely for making Chinese traditional fried foods, ${ }^{3,4}$ yet palm oil is the general choice for the instant noodle frying industry. In China, the importation and consumption of palm oil has been increasing over the past five years. The main reason is that palm oil performs well during frying due to its high heat stability, ready availability without abrupt fluctuations in supply, and price competitiveness. In addition, palm oil is used as the main oil ingredient in the commercial instant noodle flavouring oil gravy manufacturing process, accompanied by a few animal fats such as lard and 
chicken fat, and occasionally sesame oil. However, most Chinese consumers regard common palm oil as inferior and less nutritionally valuable, based on personal experience rather than scientific evaluation. Interestingly, this is also the case in some European countries, although no negative effects of palm oil consumption on human health have been demonstrated when consumed within the dietary limits of fats. ${ }^{5}$ Furthermore, some consumers do not like the fact that flavouring oil gravy in instant noodles contains animal fats based on dietary preferences or religion. Therefore, it is important to develop an alternative and superior way to promote the nutritional quality of flavouring oil gravy without decreasing the flavour and colour.

Palm oils are commercially classified according to their melting point, expressed as ${ }^{\circ}$ (degree). $5^{\circ}$ and $8^{\circ}$ palm oils indicate their melting temperature are approximately $5{ }^{\circ} \mathrm{C}$ and $8{ }^{\circ} \mathrm{C}$, respectively. Red palm oil (RPO) is a commercially available refined oil with a typical orange-red colour that contains abundant carotenoids. The RPO normally contains 500 to $750 \mathrm{mg} \mathrm{kg}^{-1}$ carotenoids, mainly consisting of $\alpha$ - and $\beta$-carotene. Indeed, there is a mixture of more than 20 carotenes in RPO, which explains its deep red colour. ${ }^{6}$ Over 5000 years of dietary history, people have realised the many advantages of using RPO in cooking and for improving the quality of life. ${ }^{7}$ Due to the abundant carotenoids, RPO has been used to improve the vitamin A status of children and women, and it also beneficially modulates oxidative stress in patients with liver cirrhosis, and elevates $\beta$-carotene, retinol, and $\beta$-carotene plasma concentrations in patients with cystic fibrosis. ${ }^{\mathbf{8} 9}$ A previous study indicated that vitamin $\mathrm{E}$ in RPO ranges from $953-955 \mathrm{mg} \mathrm{kg}^{-1}$ in the form of $\alpha$-tocopherol, and $\alpha$-, $\gamma$-, and $\delta$-tocotrienol. ${ }^{10,11}$ Following a number of rat model experiments, RPO intake was reported to protect the heart against cytotoxic effects, increase the threshold for induction of ventricular fibrillation in the hyperthyroid heart, and enhance the anti-inflammatory effects in myocardial tissue when applied in combination with rooibos. ${ }^{\mathbf{1 2 - 1 4}}$

Therefore, RPO may be suitable for upgrading the traditional oil formula used in flavouring oil gravy for instant noodles, to improve both the nutritional value and sensory properties, particularly the colour.

To date, the application of RPO in oil-based seasonings and jams, including flavouring oil gravy, has received minimal attention. In the present study, we tested specially processed RPO rich in carotene and tocotrienol to evaluate its effects on the flavouring oil gravy for instant noodles. Sensory qualities were evaluated by colour, appearance, flavour and impurity, while the physicochemical properties were evaluated using acid value, peroxide value, polar compounds. We also studied the oxidative stability with the contents of carotenoids, vitamin $\mathrm{E}$ and $\beta$-carotene as well as the induction time of gravies. RPO was compared with $5^{\circ}$ and $8^{\circ}$ palm oils, and other commercially available oils and fats.

\section{Materials and methods}

\subsection{Materials}

RPO used in this study was specially refined and supplied by Malaysian Palm Oil Co. Ltd (Shanghai, China). The two other commonly used palm oils $\left(5^{\circ}\right.$ and $\left.8^{\circ}\right)$ were supplied by Tianjin Longwei Co. Ltd (Tianjin, China). The slip melting point of RPO was $5{ }^{\circ} \mathrm{C}$, and the melting point of the two other palm oils was $5{ }^{\circ} \mathrm{C}$ and $8{ }^{\circ} \mathrm{C}$, respectively. Eleven commercial flavouring oil gravy samples were obtained from instant noodle products in China (Table 2). Based on market data and consumer preferences, we chose red sauce flavouring oil gravy and spicy beef flavouring oil gravy for experiments and comparison. For RPO, two common palm oils $\left(5^{\circ}\right.$ and $\left.8^{\circ}\right)$ were used to fully replace vegetable oils and animal fats in commercial flavouring oil gravies, and to form respective pilot flavouring oil gravies.

In total, eight flavouring oil gravies were evaluated in this study. Red sauce beef flavouring gravy (RA) and spicy beef flavouring oil gravy (SA) were purchased from local market. The other six flavouring oil gravies were red sauce beef flavouring oil gravy with $5^{\circ}$ palm oil (RP5), red sauce with $8^{\circ}$ palm oil (RP8), red sauce with red palm oil (RPR), spicy beef flavouring oil gravy with $5^{\circ}$ palm oil (SP5), spicy beef with $8^{\circ}$ palm oil (SP8), and spicy beef with red palm oil (SPR), respectively. They were formulated (Table 1) and prepared in Shanghai Pingao Co., Ltd (Shanghai, China). The producing processes of the gravy are shown in Fig. 1.

\subsection{Reagents and standards}

Absolute ethyl alcohol, $n$-hexane, absolute ether, and petroleum ether were purchased from CNW Technologies GmbH (Darmstadt, Germany). 1,4-Dioxane was ordered from Fluka (Madrid, Spain). All other solvents used for extraction and chromatographic analysis were of HPLC grade and obtained from SigmaAldrich (St Louis, MO, USA). Water was purified with a Milli-Q water purification system (Millipore Co., Ltd, Milford, UK).

Fatty acid methyl ester (FAME; Supelco 37 FAME Mix) and C18:1n7c FAME (Sigma-Aldrich) were used as standards. Four tocopherols $\left(\alpha-\mathrm{T}, \beta-\mathrm{T}, \gamma-\mathrm{T}\right.$, and $\delta$-T) and four tocotrienols $\left(\alpha-\mathrm{T}_{3}\right.$, $\beta-T_{3}, \gamma-T_{3}$, and $\delta-T_{3}$ ) were purchased from Calbiochem (SigmaAldrich, PA, USA). Tocol (internal standard) was supplied from Matreya (Pleasant Gap, PA, USA). $\beta$-Carotene and other standard compounds were obtained from Sigma-Aldrich (Fig. 2).

\subsection{Extraction of oils from commercial and pilot flavouring oil gravies}

Samples were placed in glass containers, dissolved in $n$-hexane, sonicated for $\sim 1 \mathrm{~h}$, then transferred into a Pyrex glass Soxhlet extractor. After Soxhlet extraction, excess solvent was removed under vacuum at $45{ }^{\circ} \mathrm{C}$ using a rotary evaporator (Yuanhuai Chemical Technology Co., Ltd, Shanghai, China). Straw was then used to absorb the oil from the Soxhlet extractor and transfer it into a $15 \mathrm{~mL}$ plastic centrifuge tube prior to analysis. All together, eight oil samples from the gravies and three palm oils ( $5^{\circ}$ palm oil, $8^{\circ}$ palm oil and red palm oil) were submitted for analyses.

\subsection{Analysis of acid value (AV), peroxide value (POV), and total polar compounds (TPC)}

The AV and POV of oils were determined using a titrimetric method according to the China National Standards (GB 
Table 1 The formulation of red sauce beef flavouring oil gravy and spicy beef flavouring oil gravy

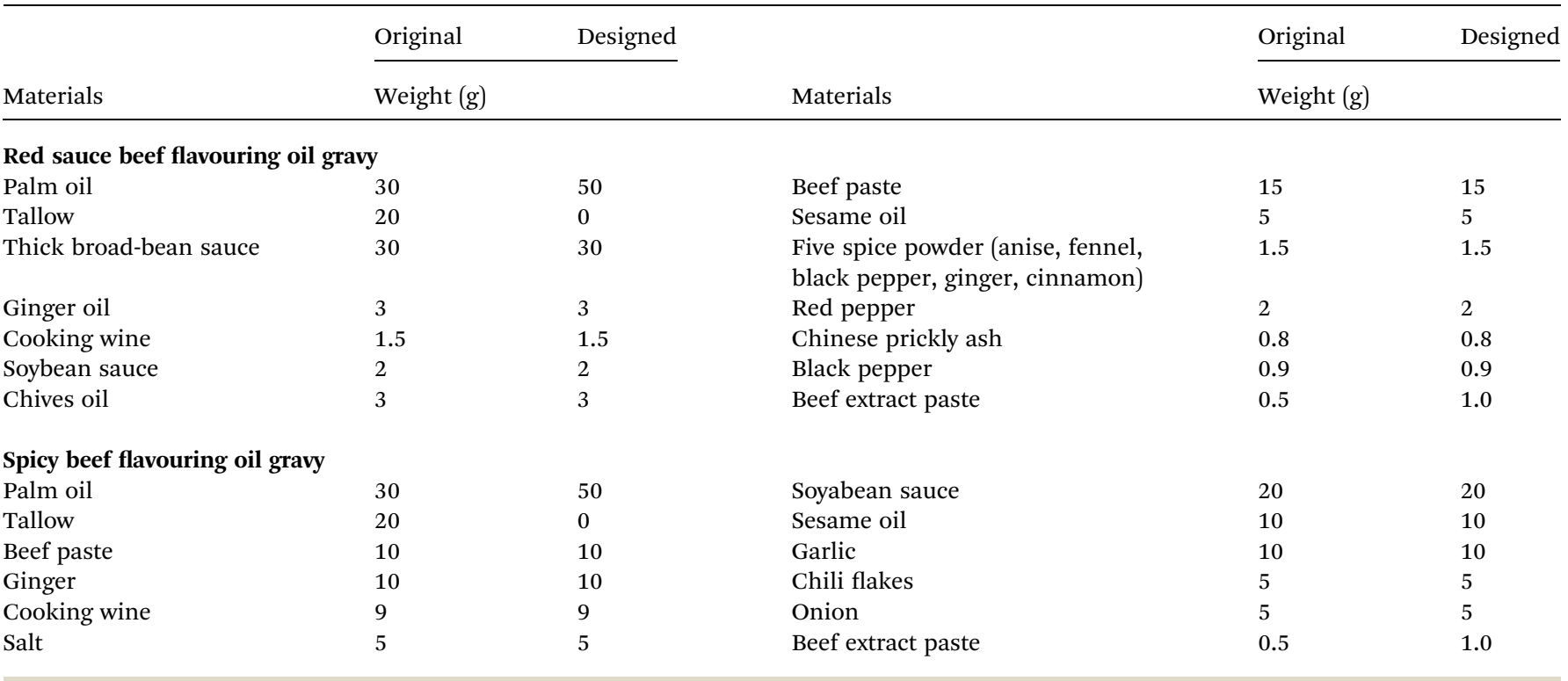

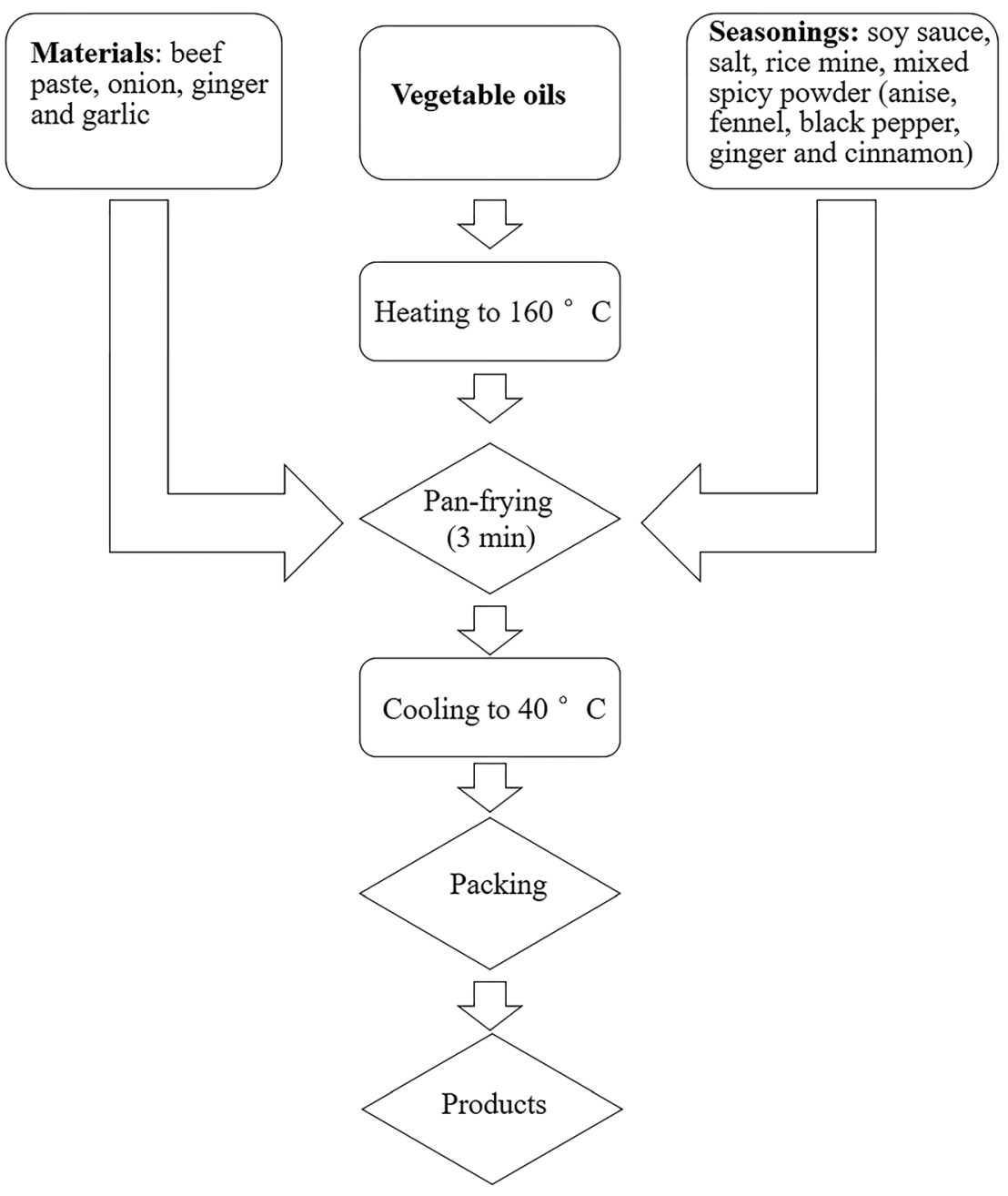

Fig. 1 Flowchart of the process of pilot flavouring oil gravies. 

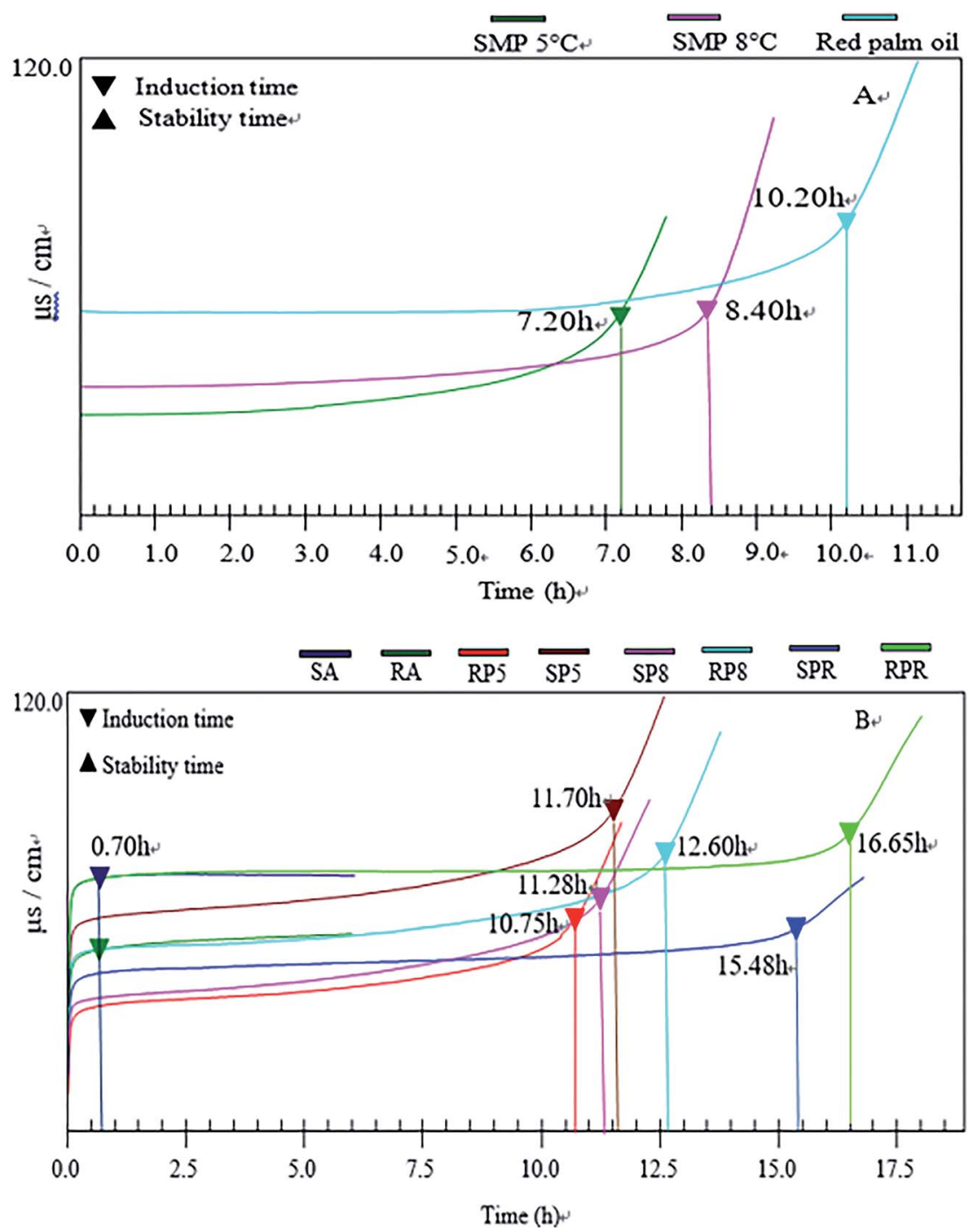

Fig. 2 The oxidation stability of palm oils and flavouring oil gravies. RA = red sauce gravy from producer $A ; S A=$ spicy flavour gravy from producer A; RP5, RP8, and RPR = pilot red sauce gravy with SMP $5^{\circ} \mathrm{C}, \mathrm{SMP} 8{ }^{\circ} \mathrm{C}$, and red palm oil, respectively; SP5, SP8, and SPR $=$ pilot spicy flavour gravy with $\mathrm{SMP} 5{ }^{\circ} \mathrm{C}, \mathrm{SMP} 8{ }^{\circ} \mathrm{C}$, and red palm oil, respectively.

5009.229-2016) and (GB 5009.227-2016), respectively, and they were expressed in units of $\mathrm{mg} \mathrm{g}^{-1}$ and $\mathrm{g} 100 \mathrm{~g}^{-1}$, respectively. Based on the manufacturer's instructions, oils were maintained above $40{ }^{\circ} \mathrm{C}$, and TPC was measured using a Testo 270 cooking oil tester (Lenzkirch, Germany), which is highly correlated with the total polar material (TPM) content. ${ }^{15}$

\subsection{Determination of colour}

Colour measurement was performed using a PilotScan spectrophotometer (Hunterpilot, Reston, VA, USA), and expressed in terms of $L^{*}, a^{*}, b^{*}$ values. Measurements were made in triplicate and results were averaged. Additionally, chroma $\left(C^{*}\right)$ was used to describe the brightness or vividness of colour (colour saturation starting from a value of 0 ) and was calculated using the formula $C^{*}=\left(a^{*^{2}}+b^{*^{2}}\right)^{1 / 2} . \Delta E$ was used to describe colour differences and was calculated using the formula

$$
\Delta E=\left[\left(L^{*}-L_{\mathrm{ref}}^{*}\right)^{2}+\left(a^{*}-a_{\mathrm{ref}}^{*}\right)^{2}+\left(b^{*}-b_{\mathrm{ref}}^{*}\right)^{2}\right]^{1 / 2}
$$

\subsection{Determination of fatty acids}

The fatty acid profile was determined according to EU standard methods (Annexes II and IX of the European Community Regulation EEC/2568/91). Fatty acid methyl esters (FAMEs) were obtained by cold alkaline trans-esterification with methanol potassium hydroxide solution and extracted with $n$-hexane. Briefly, $1 \mathrm{~g}$ of each sample was mixed with $40 \mathrm{~mL}$ of $n$-hexane, reacted with $40 \mathrm{~mL}$ of methanol potassium hydroxide solution $(0.4 \mathrm{M})$, left until homogenous ( $\sim 30 \mathrm{~min})$, and finally extracted with distilled water. The supernatant was used for gas chromatography (GC) analysis with a Focus GC instrument (Thermo Scientific, Milan, Italy) equipped with a split injector, a flame ionisation detector (FID), and a SP-2560 fused silica capillary 
column $(100 \mathrm{~cm} \times 0.25 \mathrm{~cm}$ i.d. $\times 0.02 \mu \mathrm{m}$ film thickness; Supelco, USA). Helium was used as carrier gas at an internal pressure of $110 \mathrm{kPa}$. The temperatures of the detector and injector were $275{ }^{\circ} \mathrm{C}$ and $260{ }^{\circ} \mathrm{C}$, respectively. The oven temperature was $70{ }^{\circ} \mathrm{C}$ during the first $4 \mathrm{~min}$, increased to $110{ }^{\circ} \mathrm{C}$ at $8{ }^{\circ} \mathrm{C} \mathrm{min}{ }^{-1}$, then to $250{ }^{\circ} \mathrm{C}$ at $4{ }^{\circ} \mathrm{C} \mathrm{min}{ }^{-1}$ and held for $15 \mathrm{~min}$. The split ratio was $1: 50$ and the injected volume was $1 \mu \mathrm{L}$. The results are expressed as the relative percentage of each fatty acid, calculated by internal normalisation of the chromatographic peak area. A total of 37 FAME standards and a C18:1n7c FAME standard were used for calibration and the identification of FAMEs by their retention times.

\subsection{Determination of carotenoids and vitamin $\mathbf{E}$}

The concentration of carotenoids in oils was measured as described previously. ${ }^{\mathbf{1 6}}$

The vitamin E concentration was determined by the method of Cunha, Amaral, Fernandes and Oliveira. ${ }^{17}$

For the analysis of vitamin $\mathrm{E}$ in oil sample, $1 \mathrm{~mL}$ of oil sample was mixed with $5 \mathrm{~mL} n$-hexane in a $10 \mathrm{~mL}$ centrifuge tube and the mixture was thoroughly shaken with ultrasonic wave for $10 \mathrm{~min}$. The obtained mixture was transferred into volumetric flask and diluted with $n$-hexane $(10 \mathrm{~mL})$. Then the solution was filtrated with $0.45 \mu \mathrm{m}$ film (Changzhou Yuekang Medical Equipment Co., Ltd, China) and analyzed using Agilent 1200 HPLC system (Aligent lnc Ltd, CA, USA). A chromatographic column (LiChroCART® ${ }^{\circledR}$ Si60 $250 \mathrm{~mm} \times 4 \mathrm{~mm} \times 5 \mu \mathrm{m}$, Merck KGaA Co Ltd., Germany) operating at room temperature was used for separation. The effluent was monitored using a fluorescence detector (excitation, $290 \mathrm{~nm}$; and emission, $330 \mathrm{~nm})$. The column temperature was $30^{\circ} \mathrm{C}$. The mobile phase consisted of $n$-hexane/isopropanol (99.5: 0.5, v/v). The flow rate was $0.8 \mathrm{~mL} \min ^{-1}$ and the injection volume was $25 \mu \mathrm{L}$. Tocopherols and tocotrienols were quantified by fluorescence detection based on the external standard method. The results were obtained from triplicate measurements.

The average limits of detection (LODs) of tocopherols and tocotrienols ranged from 0.0003 to $0.008 \mu \mathrm{g} \mathrm{mL} \mathrm{m}^{-1}$. The average limits of quantification (LOQs) of tocopherols and tocotrienols ranged from 0.001 to $0.026 \mu \mathrm{g} \mathrm{mL}^{-1}$. The regression coefficients $\left(R^{2}\right)$ of tocopherol and tocotrienol ranged from 0.9800 to 0.9982 . The tocopherol and tocotrienol standard calibration curves covered concentrations of $0.1-100 \mu \mathrm{g} \mathrm{mL}^{-1}$. The concentration unit used for tocopherol and tocotrienol was $\mathrm{mg} \mathrm{kg}^{-1}$. The precision reached $0.01 \mathrm{mg} \mathrm{kg}{ }^{-1}$. The average recoveries were 75.12-105.08\%. These recoveries were acceptable.

The $\beta$-carotene content was measured as described by Murkovic and Alam. ${ }^{18}$

\subsection{Measurement of the oxidation stability of oils}

The oxidation stability index (OSI) was evaluated using an automated Metrohm Rancimat model 679 OSI instrument following the AOCS Official Method Cd 12b-92 AOCS 1997. A $2.5 \mathrm{~g}$ oil sample was used in each test. The instrument was run at $120{ }^{\circ} \mathrm{C}$ and air was bubbled through the oil at a flow rate of $20 \mathrm{~L} \mathrm{~h}^{-1}$. Volatile degradation products were trapped in distilled water, which increased the water conductivity. The oxidation stability index was the time required to reach the inflection point of the conductivity curve. ${ }^{19}$

\subsection{Sensory panel evaluation}

A panel of 12 judges composed students and employees of the College of Agriculture and Biology (seven males and five females between the ages of 20 and 50 years old). Training was provided at the beginning of the first evaluation session, which lasted about 30 min. $^{20}$

Each flavouring oil gravy sample was stored in the dark at room temperature and opened immediately before sensory analysis. Disposable coded paper cups were offered to each panellist, along with a scorecard, and $5 \mathrm{~g}$ of each prepared sample was placed on a transparent vessel for evaluation of appearance (presence of impurities and appearance of organisation). Additionally, $5 \mathrm{~g}$ samples were dissolved in $1 \mathrm{~L}$ of boiling water for the evaluation of colour, and $5 \mathrm{~g}$ samples were added to $500 \mathrm{~mL}$ of boiling water for the evaluation of odour and taste. For each product, panellists scored each perceived attribute from weak (0) to strong (10). ${ }^{21}$

Evaluations were performed at room temperature $\left(18-20{ }^{\circ} \mathrm{C}\right)$ under natural light. To minimise fatigue and standardise the assessment process, a rigorous tasting and rinsing procedure was established. Judges were asked to smell and taste the flavouring oil gravy sample in the mouth for 4-5 s, split, then perform a second smell and taste test before filling out the scorecard. Judges were then asked to rinse their mouth with water, eat a piece of bread or Melba toast, rinse again with water, and wait $1 \mathrm{~min}$ before proceeding to the next sample.

\subsection{Sensory evaluation using an electronic tongue}

An electronic tongue instrument designed using nonselective inert metal sensors (platinum, gold, palladium, titanium, tungsten, and silver) was used for analysis of flavouring oil gravy samples. The aim was to analyse and compare the sensory qualities of commercial and pilot flavouring oil gravies.

Potassium hydroxide solution $(1 \mathrm{~g} \mathrm{KOH}$ in $10 \mathrm{~mL}$ ultrapure water) was prepared, and the conductivity of ultrapure water was $18.2 \mathrm{M} \Omega \mathrm{cm}$ at room temperature. A $5 \mathrm{~g}$ sample of palm oil was mixed with the appropriate volume of potassium hydroxide solution, and placed on a heating magnetic stirrer with a rotating speed of $600 \mathrm{rpm}$ for $\sim 120 \mathrm{~min}$ and at $95{ }^{\circ} \mathrm{C}$. After saponification, the solution was diluted 100 -fold and filtered prior to detection. For each test, a $10 \mathrm{~mL}$ sample was accurately prepared at room temperature, and the test probe of the electronic tongue was cleaned with ultrapure water. The electronic potential was $\pm 1 \mathrm{~V}$, the pulse separation was $200 \mathrm{mV}$, and the sensitivity of the detection was four orders of magnitude. All measurements were repeated six times and the results were averaged.

\subsection{Statistical analysis}

Data are expressed as the mean \pm SD of three independent measurements. Statistical analysis was performed using SPSS 19.0 software (Chicago, IL, USA). Analysis of variance was 
conducted using the one-way analysis of variance (ANOVA) method. Significant differences between means (at $p<0.05$ ) were determined using Duncan's multiple range tests. Data obtained from the electronic tongue and physicochemical measurement analyses were analysed by principal component analysis (PCA) for data visualisation and the detection of relationships between samples. Multivariate data analysis was applied for both qualitative and quantitative analysis.

\section{Results and discussion}

\subsection{Details of commercially available instant noodle flavouring oil gravies}

The main oils used in commercial flavouring oil gravies were palm oil, vegetable oil, and animal fats (Table 2). Except for the spicy flavouring oil gravy, the oil content was above $700 \mathrm{~g} \mathrm{~kg}^{-1}$. Palm oils are used worldwide in margarines, shortening, frying oils, and candy oils, and use in frying oils is particularly common in the food industry. One study reported that palm oils are the main vegetable oils used in food. ${ }^{22}$ Almost all instant noodle blocks and flavouring oil gravies are prepared by frying with palm oils. As shown in the Table 1, the oil content of red sauce flavouring oil gravy and spicy flavouring oil gravy was highest (above $750 \mathrm{~g} \mathrm{~kg}^{-1}$ ), which is the main reason we chose them for further investigation.

\subsection{Chemical characteristics of palm oils and oils from the gravies}

Chemical characteristics investigated in this study are listed in Table 3. The main fatty acids in palm oils are myristic acid (C14:0), palmitic acid (C16:0), stearic acid (C18:0), oleic acid (C18:1), and linoleic acid (C18:2). Myristic acid (C14:0) did not differ between original palm oils, but palmitic acid (C16:0) and oleic acid (C18:1) differed significantly $(p<0.05)$. Unsaturated fatty acid (USFA) of red palm oil is $56.52 \%, 53.98 \%$ for $5^{\circ}$ palm oil, and $50.72 \%$ for $8^{\circ}$ palm oil, while saturated fatty acid (SFA) is $43.48 \%, 46.02 \%$ and $49.28 \%$ (red palm oil, $5^{\circ}$ palm oil, $8^{\circ}$ palm oil), respectively. Palm oils contain a balanced fatty acid composition, and the saturated fatty acid content is almost equal to the unsaturated fatty acid content. ${ }^{23}$ The fatty acid composition of palm oils affects its oxidative stability, and is also relevant to its nutritional quality and the changes it undergoes during frying the USFA content in RPO $(56.62 \%)$ was higher than that in $5^{\circ}(53.98 \%)$ and $8^{\circ}$ palm oils $(50.72 \%)$, which indicates that RPO may have a positive effect on cardiovascular diseases due to its polyunsaturated fatty acids, especially linoleic acid, as claimed by Kuntom and Ariffin. ${ }^{24}$ RPO has also been shown to display protective effects against hypercholesterolemia and atherosclerotic plaque formation, despite being high in saturated fatty acids. ${ }^{13}$ As shown in Table 3 , the concentration of $\beta$-carotene in $5^{\circ}$ and $8^{\circ}$ palm oils was low, but it was highest in RPO $\left(520.00 \mathrm{mg} \mathrm{kg}^{-1}\right)$. Previous studies indicated that RPOs contain a high carotene content of up to $513-542 \mathrm{mg} \mathrm{kg}^{-1}{ }^{10,11}$ Carotenoids provide the intense yellow and orange colour, and they have been the subject of many scientific studies. Some studies found that changes in colour intensity are associated with the oxidative degradation of carotenoids, and aroma compounds are formed during the degradation of carotenoids. ${ }^{25}$ During refining, all impurities in crude oils are removed, such as undesirable odours, flavours, and colours, but beneficial components such as vitamins, pro-vitamins, and antioxidants are also removed at the same time. ${ }^{24}$ RPO contains various fatty acids, and it is also a rich source of a wide range of different lipid-soluble antioxidants such as tocopherols, tocotrienols, carotenoids, lycopene, and co-enzyme Q10, among others. The health benefits of RPO have been attributed to its unique composition of fatty acids and high levels of natural antioxidants. ${ }^{26,27}$ The vitamin E content of the three palm oils was $364.00 \mathrm{mg} \mathrm{kg}$, $347.00 \mathrm{mg} \mathrm{kg}{ }^{-1}$, and $380.00 \mathrm{mg} \mathrm{kg}^{-1-}$, and the small difference is presumably due to the addition of vitamin $\mathrm{E}$ to commercial $5^{\circ}$ and $8^{\circ}$ palm oils. Fresh original palm oils displayed the lowest PC values $(<10 \%)$, and the $\mathrm{AV}$ was $\sim 0.1 \mathrm{mg} \mathrm{g}^{-1}$ for all three palm oils, which is lower than that of the standard $\left(0.2 \mathrm{mg} \mathrm{g}^{-1}\right)$. The POV

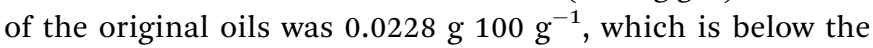

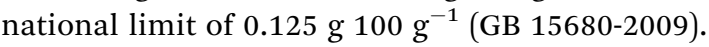

Table 2 Details of the oils and fats used in flavouring oil gravies in the main commercially available instant noodle products in China ${ }^{a}$

\begin{tabular}{|c|c|c|c|c|c|c|c|}
\hline \multirow{3}{*}{$\begin{array}{l}\text { Flavour types in flavouring } \\
\text { oil gravies }\end{array}$} & \multirow[b]{3}{*}{ Producers } & \multicolumn{4}{|l|}{ Used oils } & \multirow[b]{3}{*}{ Weight $(\mathrm{g})$} & \multirow[b]{3}{*}{ Oil content $\left(\mathrm{g} \mathrm{kg}^{-1}\right)$} \\
\hline & & \multicolumn{2}{|c|}{ Vegetable oils } & \multicolumn{2}{|c|}{ Animal fats } & & \\
\hline & & Palm oil & Sesame oil & Butter & Lard & & \\
\hline Halide fragrant & A & + & - & + & - & 18 & 744.41 \\
\hline Pickled vegetable & A & + & - & - & + & 10 & 724.11 \\
\hline Pickled beans & A & + & + & - & + & 10 & 711.30 \\
\hline Red sauce & A & + & + & + & - & 10 & 792.60 \\
\hline Tomato & A & + & - & - & + & 7 & 786.82 \\
\hline Spicy incense & A & + & - & + & + & 18 & 423.60 \\
\hline Spicy & A & + & + & + & - & 5 & 814.41 \\
\hline Pickled vegetable & B & + & - & - & + & 13 & 738.88 \\
\hline Mushroom & $\mathrm{B}$ & + & - & - & + & 5 & 721.91 \\
\hline
\end{tabular}

${ }^{a}+=$ present, $-=$ absent. 
In our study, we analysed fatty acids in eight flavouring oil gravies (Table 3). It is worth noting that the C18:0 content had significant difference between commercial and pilot flavouring oil gravies $(p<0.05)$. Gunstone $\mathrm{e}^{24}$ has reported that the content of stearic acid (C18:0) can be an effective indicator for identifying palm oil, and the mean (average) C18:0 content of palm oil ranged from $4.5-5.0 \%$. The C18:0 content of RA and SA was $15.20 \%$ and $13.60 \%$, respectively. This proved that the oils in RA and SA contained animal fat. We also found the C18:0 content of other six pilot flavouring oil gravies exceeded the mean. This may be due to the additive of beef paste into the gravy while producing. The carotenoid content was $450.00 \mathrm{mg} \mathrm{kg}^{-1}$ for RPR and $451.20 \mathrm{mg} \mathrm{kg}^{-1}$ for SPR, compared with $142.50 \mathrm{mg} \mathrm{kg}^{-1}$ for RP5, $158.60 \mathrm{mg} \mathrm{kg}^{-1}$ for SP5, $158.20 \mathrm{mg} \mathrm{kg}^{-1}$ for RP8, and $149.20 \mathrm{mg} \mathrm{kg}^{-1}$ for SP8 $(p<0.05)$. The carotenoid content of the two commercial gravies was $80.80 \mathrm{mg} \mathrm{kg} \mathrm{kg}^{-1}$ for RA and $282.70 \mathrm{mg} \mathrm{kg}^{-1}$ for SA. Thus, flavouring oil gravies containing RPO contained far higher carotenoids levels than pilot and commercial gravies without RPO. Furthermore, the $\beta$-carotene of RPR, SPR was 312.56 and $335.46 \mathrm{mg} \mathrm{kg}^{-1}$, respectively. This is significant higher than ones of gravies without RPO $(p<0.05)$. Similar to the $\beta$-carotene content, the vitamin E content of RPR and SPR was 238.38 and $256.78 \mathrm{mg} \mathrm{kg} \mathrm{kg}^{-1}$, respectively. The vitamin E content of gravies without RPO was $200.25 \mathrm{mg} \mathrm{kg} \mathrm{kg}^{-1}$ for RP8, $198.26 \mathrm{mg} \mathrm{kg}^{-1}$ for SP8, $187.25 \mathrm{mg} \mathrm{kg}^{-1}$ for RP5, and $195.36 \mathrm{mg} \mathrm{kg}^{-1}$ for SP5. The AV, POV, PC of pilot flavouring oil gravies are also shown in Table 2. The AVs of two commercial flavouring oil gravies were $1.30 \mathrm{mg} \mathrm{g}^{-1}$ for RA, $1.25 \mathrm{mg} \mathrm{g}^{-1}$ for SA. The AVs of RP5, RP8, and RPR were 1.6, 1.2, and $1.4 \mathrm{mg} \mathrm{g}^{-1}$ of oil, respectively. The AVs were $1.5 \mathrm{mg} \mathrm{g}^{-1}$ for SP5, $1.2 \mathrm{mg} \mathrm{g}^{-1}$ for SP8, and $1.7 \mathrm{mg} \mathrm{g}^{-1}$ for SPR, respectively. The AVs of eight gravies had no significant difference $(p<0.05)$. The PV is a measure of the degree of oil oxidation and is expressed in mmol of lipid peroxides. The POVs of the eight pilot fla-

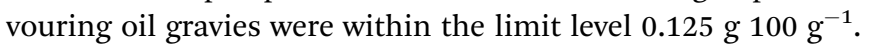

Generally, flavouring oil gravies are fried during processing, and the PC content increases during frying. The PC content was highest in the two commercial flavouring oil gravies $(\sim 15 \%)$. The high PC content of palm olein is believed to be due to the presence of high levels of diglycerides (DG; 6-8\%) compared with other oils $(2-3 \%)$. The PC content of six pilot flavouring oil gravies was ranged from $11.50-13.00 \%$, which was lower than those in commercial samples. Frying oil quality can be additionally judged by the percentage of polar compounds (PCs), and discard levels of $24-29 \%$ have been set in many countries. Therefore, none of the oils both in the commercial and pilot products were much lower than the limitation in the present work (Table 3).

\subsection{The oxidative stability of palm oils and flavouring oil gravies}

As for palm oils, the oxidative stability of RPO was better than those of $5^{\circ}$ and $8^{\circ}$ palm oil. The induction time of RPO was up to $10.20 \mathrm{~h}$, higher than $5^{\circ}$ palm oil $(21.43 \%)$ and $8^{\circ}$ palm oil (41.67\%).

Corresponding to the gravies, it was worth noting that the oxidative stability of gravies with RPO was superior to those of gravies without RPO. For six pilot gravies, the oxidative stability of six pilot gravies changed in the order: RPR $(16.65 \mathrm{~h})>$ SPR $(15.48 \mathrm{~h})>$ RP8 $(12.60 \mathrm{~h})>$ SP8 $(11.70 \mathrm{~h})>$ SP5 $(11.28 \mathrm{~h})>$ RP5 $(10.75 \mathrm{~h})$. This result may be rich carotenoids, tocopherols and tocotrienols in RPO, which contribute to the stability of RPO.

In terms of two commercial gravies, the induction time of gravies was less than $1 \mathrm{~h}$. There are a couple of possible reasons to account for the result: (i) the purchasing time of commercial gravies was near the end of shelf life, the gravies were not fresh. (ii) C18:0 content in commercial gravies exceeded the mean $4.0 \%, 15.20 \%$ for RA and $13.60 \%$ for SA, respectively (Table 3 ). The result means that commercial gravies contained much animal fat, which accelerated the oxidation process of gravies.

Comparing the oxidative stability of palm oils and gravies, it was worth mentioning that the induction time of six pilot gravies was higher than the palm oils. This may be the existence of food additive in other formula materials when producing. The specific reasons are not certain, and further study is needed for the gravies.

\subsection{The colour of commercial and pilot flavouring oil gravies}

Evaluation of flavouring oil gravy colour through sensory analysis was performed by trained expert panellists, as is common for food quality assessment. Colour measurement is used as a main index for food sensory analysis, since it informs consumers on the quality and overall acceptability of the product.

Due to the presence of butter and lard, $L^{*}$ and $b^{*}$ values for the two commercial flavouring oil gravies were higher than those of pilot flavouring oil gravies, while $a^{*}$ values were not significantly different for, except for RPR and SPR (Table 4). We found that $C^{*}$, corresponding to brightness, differed between commercial and pilot flavouring oil gravies. Previous studies reported mean $L^{*}$ values for lard and butter of 72.69 and 82.35, respectively, and $b^{*}$ values increased with the degree of fat oxidation. ${ }^{28}$ Pairwise comparison of samples was performed on $\Delta E$ values to describe colour differences (Table 4 ). The $\Delta E$ value between RA and SA was 9.02, and $\Delta E$ values and differed markedly between pilot and commercial samples. For red sauce flavouring oil gravies, the $\Delta E$ values of RP5 $v s$. RP8 and RP5 $v s$. RPR were 1.68 and 5.92, respectively, and $\Delta E$ values between RP5 vs. SP5, RP5 vs. SP8, and RP5 vs. SPR were 1.30, 4.03, and 10.62, respectively. Thus, the colour of pilot flavouring oil gravies containing RPO were significantly different from those containing $5^{\circ}$ or $8^{\circ}$ palm oils.

\subsection{Sensory evaluation of commercial and pilot flavouring oil gravies}

A cobweb diagram showing the sensory results for commercial and pilot flavouring oil gravies is shown in Fig. 3. Four factors (impurity, appearance, colour, and flavour) contributed sensory evaluation scores for two commercial and six pilot flavouring oil gravies. Impurities did not differ $(p<0.05)$ between the eight samples, but there were significant differences in appearance, colour, and flavour $(p<0.05)$. It is interesting to note that none of the four factors differed between the two commercial 
Table 4 Colour differences in commercial and experimental flavouring oil gravies ${ }^{a}$

\begin{tabular}{|c|c|c|c|c|c|c|c|c|c|c|c|c|}
\hline \multirow[b]{2}{*}{ Types } & \multicolumn{4}{|c|}{ Colour determinations } & \multicolumn{8}{|c|}{ Color difference of pair comparison } \\
\hline & $L^{*}$ & $a^{*}$ & $b^{*}$ & $C^{*}$ & RA & SA & RP5 & RP8 & RPR & SP5 & SP8 & SPR \\
\hline SA & $33.65 \pm 0.85 c$ & $21.22 \pm 0.65 b$ & $28.19 \pm 0.85 d$ & $35.30 \pm 0.28 \mathrm{e}$ & 9.02 & - & 23.62 & 23.2 & 28.86 & 24.78 & 25.85 & 32.45 \\
\hline RP5 & $11.42 \pm 0.26 b$ & $20.80 \pm 0.49 b$ & $19.52 \pm 0.88 \mathrm{c}$ & $28.53 \pm 0.25 \mathrm{~d}$ & 29.99 & 23.62 & - & 1.68 & 5.92 & 1.3 & 4.03 & 10.62 \\
\hline RP8 & $12.16 \pm 0.76 b$ & $22.08 \pm 0.80 \mathrm{~b}$ & $18.65 \pm 1.37 \mathrm{c}$ & $28.91 \pm 1.50 \mathrm{~d}$ & 29.94 & 23.20 & 1.68 & - & 6.43 & 1.92 & 3.14 & 10.43 \\
\hline SP8 & $11.78 \pm 0.74 b$ & $20.78 \pm 0.87 b$ & $15.57 \pm 0.96 b$ & $25.98 \pm 0.12 b c$ & 32.89 & 25.85 & 4.03 & 3.14 & 4.93 & 3.02 & - & 7.68 \\
\hline SPR & $6.40 \pm 0.23 a$ & $18.30 \pm 1.35 \mathrm{a}$ & $10.84 \pm 0.68 \mathrm{a}$ & $21.26 \pm 1.51 \mathrm{a}$ & 39.57 & 32.45 & 10.62 & 10.43 & 5.54 & 9.47 & 7.68 & - \\
\hline
\end{tabular}

${ }^{a} \mathrm{RA}=$ red sauce gravy from producer A; SA = spicy flavour gravy from producer A; RP5, RP8, and RPR = experimental red sauce gravy with SMP $5{ }^{\circ} \mathrm{C}$, SMP $8{ }^{\circ} \mathrm{C}$, and red palm oil, respectively; SP5, SP8, and SPR = experimental spicy flavour gravy with SMP $5{ }^{\circ} \mathrm{C}$, SMP $8{ }^{\circ} \mathrm{C}$, and red palm oil, respectively; results are given as mean \pm standard deviation $(n=3)$; different letters in the same column represent significant differences at $p<0.05$.

samples. Colour and flavour scores for pilot flavouring oil gravies containing $8^{\circ}$ palm oil (RP8 and SP8) were highest (Fig. 3). RPO gave oils a deep reddish orange-colour, due to the presence of carotenoids. After refining, many of the carotenoids are lost, and the oil becomes much blander and odourless. The process of refining also removes volatile aroma flavour

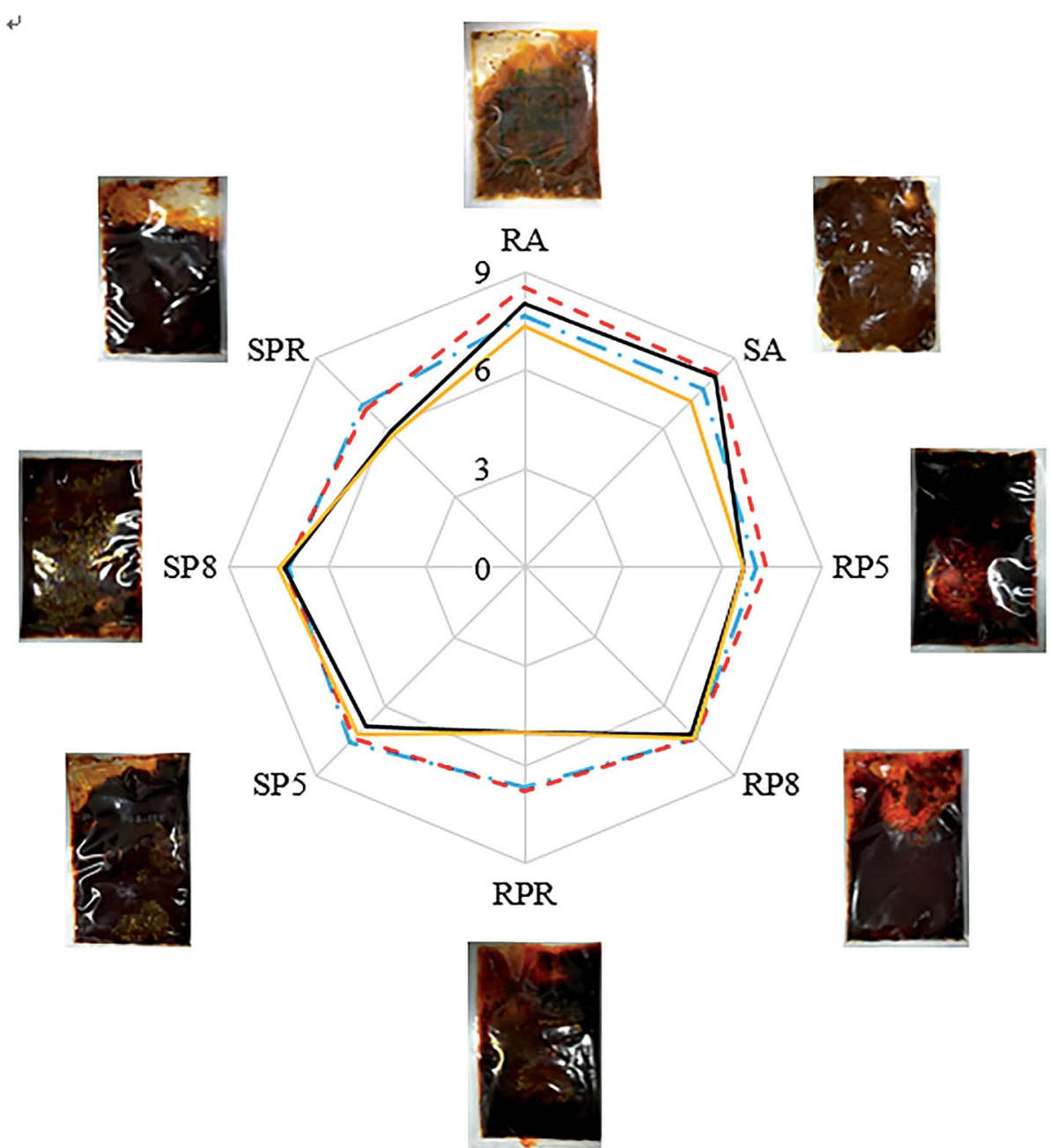

- - Impurity - - Appearance Color - Flavor

Fig. 3 Cobweb of sensory evaluation of commercial and pilot flavouring oil gravies. RA = red sauce gravy from producer $A$; SA $=$ spicy flavour gravy from producer $\mathrm{A}$; RP5, RP8, and RPR = pilot red sauce gravy with SMP $5{ }^{\circ} \mathrm{C}, \mathrm{SMP} 8{ }^{\circ} \mathrm{C}$, and red palm oil, respectively; SP5, SP8, and SPR $=$ pilot spicy flavour gravy with SMP $5{ }^{\circ} \mathrm{C}$, SMP $8{ }^{\circ} \mathrm{C}$, and red palm oil, respectively. 
compounds, and the resultant product is less appealing and tastes oilier. Samples on the same dimension were considered to have similar sensory properties. Impurities among the eight samples lie on the same dimension, indicating no differences, whereas colour and flavour within eight flavouring oil gravy are clearly different $(p<0.05)$.

\subsection{PCA of electronic tongue and physicochemical quality data}

Fig. 4A and B shows the results of PCA of e-tongue data on commercial and pilot flavouring oil gravies (Fig. $4 \mathrm{~A}=$ pilot red sauce flavouring oil gravies; Fig. $4 \mathrm{~B}=$ pilot spicy flavouring oil gravies). The four flavouring oil gravies have obvious differences. From Fig. 4A, we see that PC1 and PC2 together account for $98.97 \%$ of the variation. The repeatability of the four samples was high, and was highest for RPR. The distance represents the similarity between samples, and RP8, RP5, and RA are grouped into a cluster, indicating similarities between them. Fig. 3B shows that the cumulative contribution of PC1 and PC2 was $98.42 \%$, and the repeatability of SP5 was highest. SP5, SA, and SPR form a cluster, indicating high similarity. PCA could therefore be used to confirm differential characteristics and behaviour, and provide a better representation of sample similarity. Furthermore, the e-tongue method could effectively differentiate between the eight flavouring oil gravies. These results are similar to those reported by a previous study. ${ }^{29}$ Samples sharing similar taste characteristics were previously reported using a similar PCA approach, ${ }^{30}$ and e-tongue technology has been used successfully for discrimination of Korean rice wines. ${ }^{31}$ Unsupervised as well as supervised statistical techniques can be used to analyse the ability electronic tongue instruments to discriminate qualitatively between tomato cultivars. ${ }^{21}$ Thus, our study also testified that the e-tongue can be used in future studies to differentiate flavouring oil gravies containing RPO.

Fig. 4C and D shows the results of PCA of physicochemical quality data (Fig. 4C = distribution and correlation between responses in vector space, Fig. $4 \mathrm{D}=$ PCA analysis of the analytical determination of eight different flavouring oil gravies). We chose a significance level of $10 \%$, since erroneously accepting an attribute as significant at this level was not considered to be critical. Carotenoids accounted for the highest percentage in component 1 , while $L^{*}$ was the major factor in
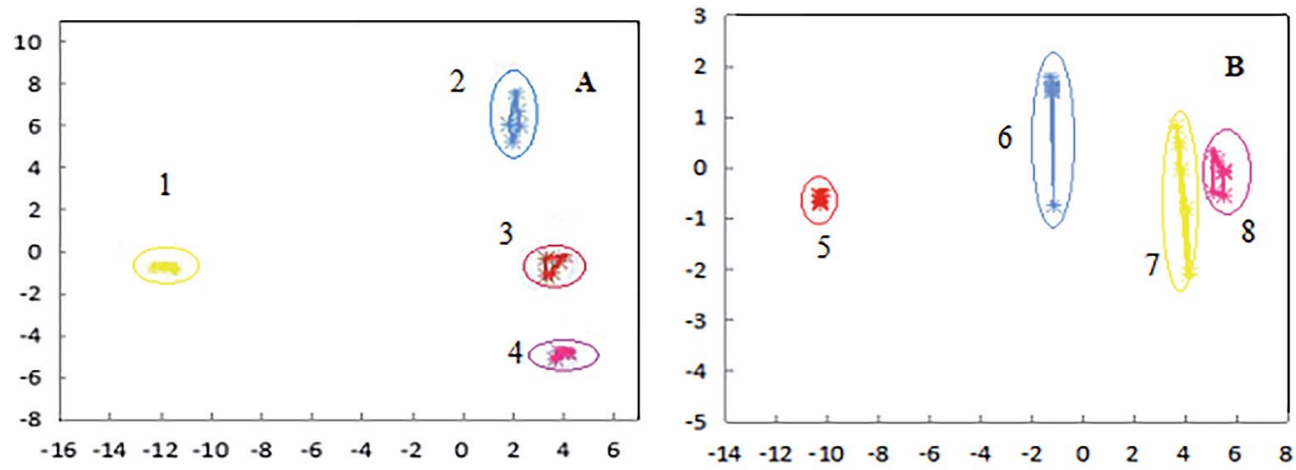

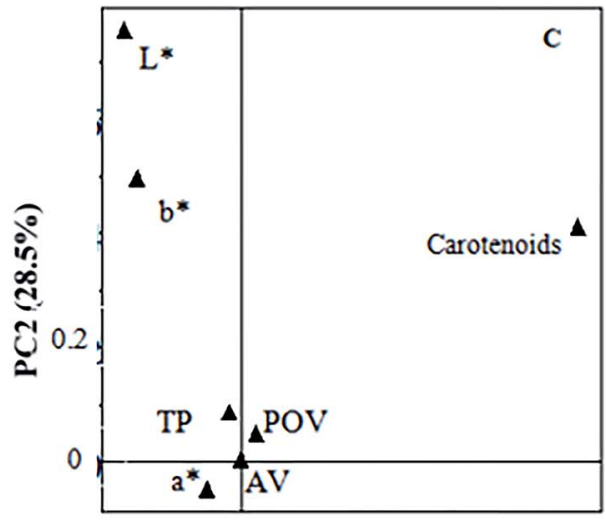

$\mathrm{PCl}(69.5 \%)$

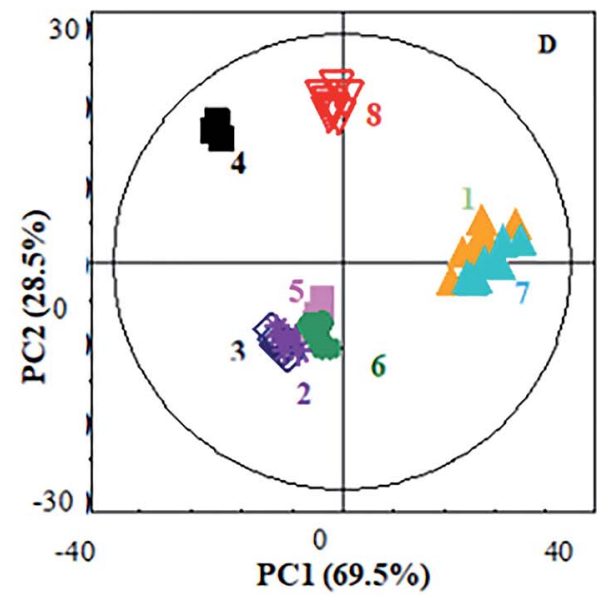

$\operatorname{PCl}(69.5 \%)$

Fig. 4 Principal component analysis (PCA) analysis of electronic tongue and physicochemical quality data. (A) Red sauce flavouring oil gravies; (B) spicy sauce flavouring oil gravies; (C) distribution and correlation between responses in vector space; (D) PCA analysis of the analytical determination of eight different flavouring oil gravies. (1) Pilot red sauce flavouring oil gravy with RPO; (2) pilot red sauce flavouring oil gravy with $8^{\circ}$ palm oil; (3) pilot red sauce flavouring oil gravy with $5^{\circ}$ palm oil; (4) commercial red sauce flavouring oil gravy; (5) pilot spicy flavouring oil gravy with $5^{\circ}$ palm oil; (6) pilot spicy flavouring oil gravy with $8^{\circ}$ palm oil; (7) pilot spicy flavouring oil gravy with RPO; (8) commercial spicy flavouring oil gravy. 
component 2, suggesting these may be useful for distinguishing samples. $\mathrm{AV}, \mathrm{PV}$, and $a^{*}$ had minimal influence on the plots for all eight samples (Fig. 4C). In the PCA score plots of physicochemical data, PC1 and PC2 accounted for 98\% of the total variance. The observed perpendicular orientations suggest these two groups of variables are unrelated to one another. In general, the plots indicated clear differences in physicochemical properties between the eight samples (Fig. 4D).

\section{Conclusion}

In this study, we investigated the seasoning accompanying commercially available instant noodles. Palm oils major oils using in commercial flavouring oil gravies, and the oil content is generally over $700 \mathrm{~g} \mathrm{~kg}^{-1}$. RPO has a unique composition of fatty acids which are attributed to health benefits, and high levels of natural antioxidants such as vitamin $\mathrm{E}$ and carotenoids that benefit quality of life. The carotenoid concentration in pilot flavouring oil gravies containing RPO were higher than in pilot and commercial gravies without RPO. The oxidative stability of gravies formulated with RPO was superior to those without RPO. PCA of e-tongue data revealed higher repeatability for pilot flavouring oil gravies containing RPO, and the e-tongue method could effectively distinguish between the eight flavouring oil gravies tested, and could determine whether RPO was present. Although RPO contains high levels of natural antioxidants that benefit quality of life, it has a bitter flavour and a high production cost. In the present study, RPO enhanced the carotenoid content of flavouring oil gravy without negatively influencing the sensory qualities. Instant noodle nutritional quality and the gravy oxidative stability can therefore be improved by replacing oil ingredients with RPO.

\section{Conflicts of interest}

All authors declare no conflicts of interest.

\section{Acknowledgements}

This work was supported by the National Natural Science Foundation of China (No. 31471668 and 31671958), PORTSIM (No. 038/2015), and the Agri-X Fund of Shanghai Jiao Tong University (No. Agri-X2015007).

\section{References}

1 N. Gulia, V. Dhaka and B. Khatkar, Crit. Rev. Food Sci. Nutr., 2014, 54, 1386-1399.

2 I. S. Huh, H. Kim, H. K. Jo, C. S. Lim, J. S. Kim, S. J. Kim, O. Kwon, B. Oh and N. Chang, Nutr. Res. Pract., 2017, 11, 232-239.

3 G. Li, S. M. Wu, J. X. Zeng, L. Wang and W. J. Yu, Food Chem., 2016, 209, 123-130.

4 X. Zhao, S. M. Wu, G. Y. Gong, G. Li and L. Zhuang, Food Control, 2017, 75, 99-107.

5 F. Marangoni, C. Galli, A. Ghiselli, G. Lercker, C. La Vecchia, C. Maffeis, C. Agostoni, D. Ballardini, O. Brignoli, P. Giacco,
C. Macca, P. Magni, G. Marelli, W. Marrocco, V. L. Miniello, G. F. Mureddu, N. Pellegrini, R. Stella, E. Troiano, E. Verduci, R. Volpe and A. Poli, Int. J. Food Sci. Nutr., 2017, 68, 643-655. 6 O. O. Oguntibeju, A. J. Esterhuyse and E. J. Truter, Br. J. Biomed. Sci., 2009, 66, 216-222.

7 B. J. Burri, Compr. Rev. Food Sci. Food Saf., 2012, 11, 221-232.

8 R. Catanzaro, N. Zerbinati, U. Solimene, M. Marcellino, D. Mohania, A. Italia, A. Ayala and F. Marotta, HBPD Int, 2016, 15, 165-172.

9 C. Zhu, Y. Cai, E. R. Gertz, M. R. La Frano, D. J. Burnett and B. J. Burri, Nutr. Res., 2015, 35, 965-974.

10 E. Dauqan, H. A. Sani, A. Abdullah, H. Muhamad and A. G. M. Top, Am. J. Appl. Sci., 2011, 8, 407-412.

11 J. Yi, M. L. Andersen and L. H. Skibsted, Food Chem., 2011, 127, 1792-1797.

12 B. S. Bačová, C. Vinczenzová, J. Žurmanová, D. Kašparová, V. Knezl, T. E. Beňová, S. Pavelka, T. Soukup and N. Tribulová, Histochem. Cell Biol., 2017, 147, 63-73.

13 E. Katengua-Thamahane, J. L. Marnewick, O. R. Ajuwon, N. N. Chegou, G. Szücs, P. Ferdinandy, T. Csont, C. Csonka and J. Van Rooyen, J. Inflammation, 2014, 11, 41.

14 A. Wergeland, D. Bester, B. Sishi, A. Engelbrecht, A. Jonassen and J. Van Rooyen, Cell Biochem. Funct., 2011, 29, 356-364.

15 J. Song, M. J. Kim, Y. J. Kim and J. Lee, Food Chem., 2017, 220, 306-312.

16 A. M. Goula, M. Ververi, A. Adamopoulou and K. Kaderides, Ultrason. Sonochem., 2017, 34, 821-830.

17 S. C. Cunha, J. S. Amaral, J. O. Fernandes and M. B. P. Oliveira, J. Agric. Food Chem., 2016, 54, 3351-3356.

18 M. Murkovic and Z. Alam, Food Res. Int., 2013, 50, 534-544. 19 Z. Fan and J. Krahl, Fuel, 2017, 195, 123-130.

20 H. S. Kwak, B. H. Ahn, H. R. Kim and S. Y. Lee, J. Food Sci., 2015, 80, S161-S170.

21 K. Beullens, P. Mészáros, S. Vermeir, D. Kirsanov, A. Legin, S. Buysens, N. Cap, B. M. Nicolai and J. Lammertyn, Sens. Actuators, B, 2008, 131, 10-17.

22 K. T. Tan, K. T. Lee, A. R. Mohamed and S. Bhatia, Renewable Sustainable Energy Rev., 2009, 13, 420-427.

23 F. D. Gunstone, Palm Oil, Vegetable Oils in Food Technology: Composition, Properties and Uses, Wiley-Blackwell, 2011, vol. 55 , pp. 25-28.

24 A. Kuntom, A. A. Ariffin, Y. H. Hui, F. Chen, L. M. L. Nollet and R. P. F. Guine, Flavors of Palm Oil, Handbook of Fruit and Vegetable Flavors, John Wiley \& Sons, Inc., 2010, pp. 1051-1070.

25 M. F. Nonier, N. V. de Gaulejac, N. Vivas and C. Vitry, C. R. Chim., 2004, 7, 689-698.

26 B. Nagendran, U. Unnithan, Y. Choo and K. Sundram, Food Nutr. Bull. Suppl., 2010, 21, 189-194.

27 L. Packer, S. U. Weber and G. Rimbach, J. Nutr., 2001, 131, 369S-373S.

28 F. J. Méndez-Cid, J. M. Lorenzo, S. Martínez and J. Carballo, Food Chem., 2017, 217, 743-749.

29 X. Cetó, A. González-Capilotuig, J. Capdevila, A. Puig-Pujol and M. del Valle, Sens. Actuators, B, 2015, 207, 1053-1059.

30 Z. Wei and J. Wang, Electrochim. Acta, 2011, 56, 4907-4915.

31 B. S. Kang, J. E. Lee and H. J. Park, Food Chem., 2014, 151, 317-323. 